\title{
Faraway suture technique in hypospadias repair
}

\author{
Ahmed E Lasheen* \\ General \& Laparoscopic Surgery Department, Faculty of Medicine, Zagazig University, Egypt
}

Received: 20 January, 2020

Accepted: 18 February, 2020

Published: 19 February, 2020

*Corresponding author: Ahmed E Lasheen, General and Laparoscopic Surgery Department, Zagazig University Hospital 44519, Egypt, Tel: 0020552343035 ;

E-mail: lasheenahmed@yahoo.com

Keywords: Faraway suturing; Hypospadis repair https://www.peertechz.com

\section{Check for updates}

\begin{abstract}
Background: The complications after hypospadias repair still occurred in spite of much advancement of type of suture materials and suture techniques. This study offers new suture technique trying to improve the outcome of hypospadias repair.

Methods: This study included 23 hypospadias cases (11 distal penile, 7 mid penile, 5 proximal penile hypospadias). The standard Tabularized Incised Plate (TIP) technique was used in all cases, but the suture technique is faraway, where the two suture limbs passed under the urethral edges. Every suture was tied faraway of urethral edges by about $1 \mathrm{~cm}$ on one side. Then, the penile skin closed as usual. Lasheen urethral stent was used for two weeks. The mean follow up period was $12 \mathrm{months}$.

Results: The Suture is transverse mattress, the distance between its limbs and every suture was about $3 \mathrm{~mm}$. when these sutures were tied bring more soft tissue in midline and inversion urethral plate edges inside the urethra. Healing period was 2 weeks. No urethra-cutaneous fistula or meatal stenosis or penile curvature were noticed during period of follow up.
\end{abstract}

Conclusion: Faraway suture technique in hypospadias repair is easy, has short learning curve, and associated with good physiological urethra and penile anatomy.

\section{Introduction}

In hypospadias the urethral meatus open at ventral surface of penis or perineum other than the glans tip. Hypospadias is the most common congenital anomalies (0.3\%) of external male genitalia [1]. Hypospadias correction is surgical and still represents challenge in reconstructive surgery [2]. Complications of hypospadias repair are many as urethral fistula, urethral stenosis, complete failure, and meatal stenosis, and ranged from 13 to $64 \%[3,4]$. Many risk factors are well known as severity of hypospadias and repair technique, but still other factors are underestimated [5,6]. Suture method of every hypospadis repair is important step which affect the outcome of surgery. This study offers faraway suture technique in hypospadias repair.

\section{Patients and methods}

The idea of this study was approved by Ethical Committee of General Surgery Department, Zgazig University, Egypt at January 2018. Twenty three hypospadias patient (11 distal penile, 7 mid penile, 5 proximal penile hypospadis cases) were included in this study. The standard TIP was used in all cases, but suture technique to incised plate is different (faraway suture technique). The suture take from $1 \mathrm{~cm}$ on one edge of urethral plate, go through soft tissue under both the urethral edges. The needle and thread (Vicryle 4/0) appear on $1 \mathrm{~cm}$ of other urethral edge and return back to make other suture limb (transverse mattress suture). Multiple faraway sutures were taken to reconstruct neo-urethra and configurate normal glans Figures 1,2. After finishing of putting enough number of faraway sutures, the sutures were tied and penile skin closed as usual TIP technique. Lasheen urethral stent [7] was stay in its position for 2 weeks Figures 3,4. The follow up period ranged from 6 to 16 months (mean was 12 months).

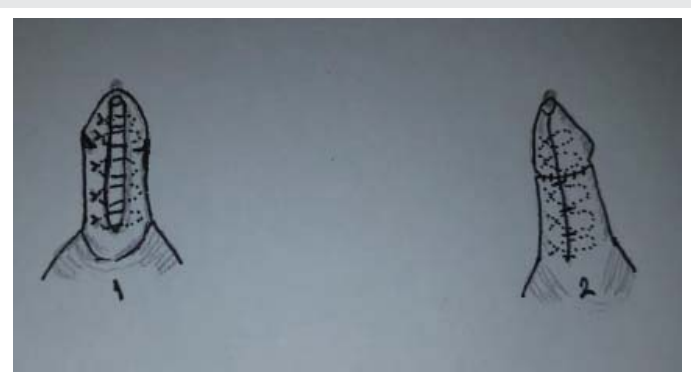

Figure 1: 1. Five faraway sutures were put on both sides of neo-urethra and before tying. 2. All sutures were tied and reconstructed neo-urethra with lasheen urethral stent in right position. 


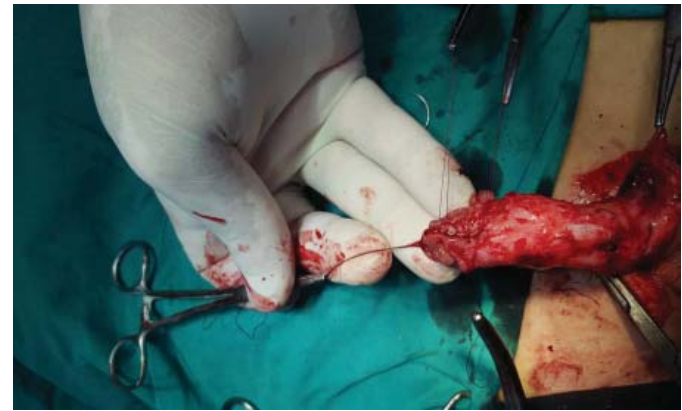

Figure 3: Three faraway sutures were put on both sides of reconstructed urethra.

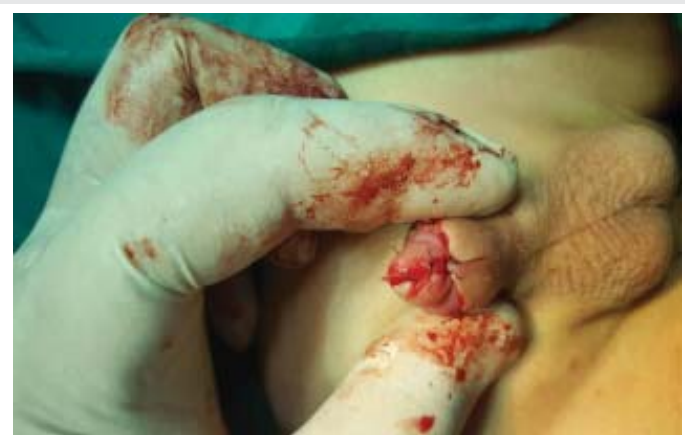

Figure 4: The faraway sutures were tied and penile skin sutured in normal position. The lasheen urethral stent was put in right position and just protruded from neourethral meatus.

\section{Results}

The number of sutures was varied according to distance between urethral opening and glans tip. The distance between every suture and other was about $3 \mathrm{~mm}$. The urethral edges were inverted inside the urethra when sutures tied. The wound healed well within two weeks. No deep infection or abscess formation noticed in any cases. The technique was comfortable in all cases. No urethral fistula or meatal stenosis or urethral stricture were reported during period of follow up.

\section{Discussion}

Many techniques and their modifications are presented for hypospadias repair to improve outcome results $[8,9]$. The most serious and common complications are urethral fistula and complete failure of technique. Known factors were accused for occurring of these complications as distance between urethral opening and glans tip, presence of chordee, and scar at ventral aspect of penis $[10,11]$. But until now other risk factors still are unknown [6]. I think the suture technique is one of these risk factors. When, the sutures were putting on both urethral plate edges will leading to eversion of urethral plate edges into soft tissue with occurring of urethral fistula. More than this, much stitches on the urethral plate edges can be producing ischemia and complete failure or fistula. The urethral edges sutures debris reacted as foreign bodies producing deep infection and abscess formation or stitch sinus followed by urethracutaneous fistula. Our suture technique in hypospadias repair, was done faraway of urethral plate edges. The suture limbs passed under the urethral plate. So, when the suture limbs were tied leading to inversion of urethral edges inside the urethra and maintain the blood supply of edges producing good healing in short time. The knots were lying faraway of reconstructed urethra no sutures debris leading no reaction and no deep infection.

\section{Conclusion}

Our suture technique in hypospadias repair has short learning curve and associated with good results and free of complications.

\section{References}

1. Lambert SM, Snyder HM, Canning DA (2011) The history of hypospadias and hypospadias repairs. Urology 77: 1277-1283. Link: http://bit.ly/39MVddl

2. Kalfa N, Paris F, Philibert B, Philibert P, Orsini M, Broussous S, et al. (2015) Is hypospadias with prenatal exposure to endocrine disruptors? A French collaborative controlled study of a cohort of 300 consecutive children without genetic defect. Eur Urol 68: 1023-1030. Link: http://bit.ly/325xF0M

3. Schneuer FG, Holland AJA, Pereira G, Bower C, Nassar N (2015) Prevalence repair and complications of hypospadias: an Australian population-based study. Arch Dis Child 100: 1038-1043. Link: http://bit.ly/39JXFkV

4. Gilliver Sc, Ashcroft GS (2007) Sex steroids and cutaneous wound healing the contrasting influences of estrogens and androgens. Climacteric 10: 276-288. Link: http://bit.ly/3294jPh

5. Chua ME, Kim JK, Rivera KC, Ming JM, Flores F, et al. (2019) The use of postoperative prophylactic antibiotics in stented distal hypospadias repair: a systemic review and meta-analysis. J Pediatr Urol 15: 138-148. Link: http://bit.ly/2V4bSFe

6. Bhat A, Mandal AK (2008) Acute postoperative complications of hypospadias repair. Indian J Urol 24: 241-248. Link: http://bit.ly/2V2RV1G

7. Lasheen $A E$ (2019) Internal urethral stent (Lasheen urethral stent) for hypospadias repair. J Surg Surgical Res 5: 68-70. Link: http://bit.ly/2SIqDw9

8. Ciftci I, Gunduz M, Sekmenli T (2019) Modified Hinderer's technique for serious proximal hypospadias with ventral curvature : outcomes and our experience. Urol J Decn 16: 478-481. Link: http://bit.ly/37ACDnn

9. Kagantsov IM, Surov RV (2018) Modification of two-stage technique of bracka with preservation and tabularization of the urethral plate for repair of proximal hypospadias. Urologia 5: 81-87. Link: http://bit.ly/39LnLUH

10. AtanA, Aykac A, Baran O, Sunay M (2019) Fixation of the glans penis and urethral catheter to the abdominal skin to avoid wound dehiscence after a hypospadias surgery: A comparative study. Turk J Urol 45: 104-107. Link: http://bit.ly/37GMQPo

11. Canning DA (2019) Re: Early Vs late-presenting urethroplasty complications after hypospadias repair. J Urol 201: 430. Link: http://bit.ly/3bS3EpE

Copyright: () 2020 Lasheen AE. This is an open-access article distributed under the terms of the Creative Commons Attribution License, which permits unrestricted use, distribution, and reproduction in any medium, provided the original author and source are credited. 